\title{
Problem Solving Style and Coping Strategies: Effects of Perceived Stress
}

\author{
Margaraet Maghan \\ Rutgers University, Newark, NJ, USA \\ Email:mmaghan@psychology.rutgers.edu
}

How to cite this paper: Maghan, M. (2017). Problem Solving Style and Coping Strategies: Effects of Perceived Stress. Creative Education, 8, 2332-2351.

https://doi.org/10.4236/ce.2017.814160

Received: September 1, 2017

Accepted: November 27, 2017

Published: November 30, 2017

Copyright $\odot 2017$ by authors and Scientific Research Publishing Inc. This work is licensed under the Creative Commons Attribution International License (CC BY 4.0).

http://creativecommons.org/licenses/by/4.0/

\begin{abstract}
One hundred and seven community college students completed VIEW: An Assessment of Problem Solving Style and the COPE Inventory. They then were randomly assigned to one of three groups. Group 1 received a vignette of a more serious personal problem. A second group was given a vignette depicting a less stressful problem situation. The third group was given a simple passage about a geography topic. On VIEW, Developer- and Internal problem-solving-styled participants across all conditions reported higher stress ratings, suggesting greater sensitivity to stressful situations. Additionally, there were significant correlations between the VIEW and COPE scores, suggesting that Explorer-, External-, and a Task-oriented problem-solving-styled individuals were more likely to use Restraint as a coping strategy, all of which suggest that in the context of a personal problem, individuals may be more likely to recognize that any solution will take time to solve, perhaps requiring "new thinking" (Explorer style), help from others (External style), and "hard" choices to be made (a Task-oriented decision-making style).
\end{abstract}

\section{Keywords}

Problem Solving Style VIEW, Coping, Stress, Creativity

\section{Introduction}

Human problem solving has long been an important area of research in education and psychology (Dewey, 1910; Johnson, 1955/1972; Polya, 1945/1957; Rossman, 1931; Wallas, 1926). Modern theories and research into problem solving have been dominated by cognitive and information processing approaches (Neisser, 1966; Newell \& Simon, 1972; Isaksen \& Treffinger, 2004). Theorists have used different vocabularies, but there are significant parallels among may 
descriptions of the problem solving process. Commonalities include such problem solving "stages" as initial awareness or sensitivity to a difficulty, specific efforts to define the problem and identify relevant aspects of the problem, gathering additional data, generating hypotheses or solution possibilities, and testing those hypotheses (Bransford \& Stein, 1984; Guilford, 1967; Hayes, 1981; Treffinger, 1988).

The focus of much of the study of human problem solving has been on cognitive strategies and techniques that bring an individual from a novice to an expert learner or performer in a particular domain area (Anderson, 1982; Borko \& Livingston, 1989; Sternberg \& Horvath, 1995). Consequently, much has been learned about the range of cognitive skills and processes of problem solving, differences between masters or experts in a domain and novices, and strategies that can be learned to improve problem solving skills (Isaksen \& Treffinger, 2004).

In recent years, however, a complement to research on skills and strategies has become theory and research into problem solving style (Basadur, Graen, \& Wakabayshi, 1990; Isaksen \& Dorval, 1993; Kirton, 1994). Researchers into style make what is termed the "level-style" distinction; that is, the focus is on the manner by which a person approaches and works on a problem, not simply how well a person solves a problem (Isaksen \& Treffinger, 2004; Selby, Treffinger, Isaksen, \& Lauer, 2004; Sternberg, 2000; Treffinger, Isaksen, \& Dorval, 2006).

Selby, Treffinger, Isaksen and Crumel (2007) describe six problem solving styles. When faced with a problem situation, Explorers are likely to "break away from the system and redefine the problem." On the other hand, Developers are likely to "stay within the existing paradigm or system, follow rules and procedures as given." Selby et al. (2007) refer to these two styles as an individual's Orientation to Change. Style is a variable on a continuum and individuals can have strong preferences, moderate preferences, slight or no preferences for Explorer or Developer styles.

Two more styles refer to the Manner of Processing information. Internal processors are likely to "want time to think about options before discussing them" with others, whereas External processors are likely to begin "talking about options right away" and actually "derive energy from interaction[s] with others." The fifth and sixth styles, respectively, describe ways individuals make decisions. The dimension of Ways of Deciding includes Person-oriented and Task-oriented styles. Person-oriented decision makers give primary attention to factors that "will promote harmony and positive relationships." They are "sensitive to people's feelings" and will give weight to "the personal or interpersonal impact" of a particular decision. In contrast, Task-oriented decision makers give weight to "what [is] logical or rational." They "consider objective, authoritative, and verifiable" criteria when choosing among alternatives.

"Style" research has found application in other fields as well. For example, psychologists and counselors have described constructs such as "coping style" that affect the ways individuals respond and deal with stressful situations. 
Among the notable efforts in this area is the work of Lazarus and Folkman (1984); Folkman \& Lazarus (1988). Lazarus and Folkman (1984) have defined coping as a "constantly changing cognitive and behavioral effort to manage specific external and internal demands that are appraised as taxing or exceeding the resources of the person" (p. 99). Lazarus and Folkman identified eight methods of coping that individuals may use when dealing with a stressful situation. They include confronting coping, distancing, self-control, seeking social support, accepting responsibility, escape-avoidance, planned problem-solving, and positive appraisal. From these eight ways of coping, Lazarus and Folkman theorized two basic styles of coping: Problem-focused and Emotion-focused Coping.

In Problem-focused Coping, the individual perceives that the stressor is something about which action can be taken (e.g. finishing a report). Problem-focused Coping activities are engaged in by individuals who perceive problems as "opportunities for benefit or gain, ...believe that problems are solvable, ... and believe \{in their\} personal ability to solve problems successfully" (p. 105). In Problem-focused Coping, an individual sees that steps can be taken to alter the stressful situation. These efforts involve risk taking and various cognitive problem solving skills.

On the other hand, Lazarus and Folkman suggest that Emotion-focused Coping involves stressful situations that cannot be readily resolved by a person's actions. In Emotion-focused Coping, the individual is focused on the emotion related to the stressful situation rather than the situation. Emotion-focused Coping activities are engaged in by individuals in a "hurried," "narrow," and "incomplete" manner. Such a disposition leads an individual into considering relatively few alternatives and applications being poorly conceived, monitored, or evaluated. The situation is not seen as something that the individual has any personal control over (Lazarus \& Folkman, 1984). Finally, there is a third typeAvoidance Coping. Avoidance activities involve, "procrastination, passivity, or inaction, and dependency." An individual who rates high on these types of activities, "puts off solving problems as long as possible, waits for problems to resolve themselves, and attempts to shift responsibility to others" (Lazarus, \& Folkman, 1984).

Carver, Scheier, and Weintrub (1989) developed COPE, an instrument to assess these three styles and several subscales contributing to the three. These subscales include such styles/strategies as active coping, planfulness, restraint, use of social supports to aid problem solving, and suppression of competing responses as part of Problem-focused Coping. Seeking emotional support, acceptance, denial, turning to religion, and positive reinterpretation-personal growth are subscales for Emotion-focused coping. Venting emotions and mental and behavioral disengagement are less useful (Avoidance) styles/strategies.

A comparison of VIEW and the COPE instrument described above suggests commonalities. A more Problem-focused style of coping with a stressful problem situation, with emphasis on planfulness, for example, may involve the same 
disposition as the VIEW Developer and/or Task-oriented styles. In contrast, an Explorer style on VIEW, with its disposition to generate many alternatives and/or entertain many different types and sources of information, may be similar to the Restraint or Avoidance coping style in the sense that action is deferred.

An emphasis on either instrumental or emotional social support may be more likely for an individual with a VIEW External processing style or Person-oriented Deciding style. An Internal problem solving style also might share dispositions of Restraint or Positive Reinterpretation and Growth, which appear in coping theory to be more inner-directed and/or insightful-like activities. Therefore, the purpose of the present study was to examine the relationship between problem solving style and strategies of coping that students prefer in response to perceived stressful problems that they might encounter.

\section{Method}

\subsection{Participants}

One hundred and seven freshmen and sophomore undergraduate students from a small public community college participated on a volunteer basis in this study. Their average age was 23.25 (SD = 7.99). Of 94 participants who self-reported a grade-point average, the mean was 2.99 out of $4.00(\mathrm{SD}=.745)$. Approximately 63.9\% of participants were Caucasian, 7.6\% African American, 11.7\% Hispanic, $2.8 \%$ Asian, and $13.2 \%$ were from other ethnic backgrounds. The gender split was 78 (approximately 80\%) female and 29 (approximately 20\%) male. The majority of students were considered to be middle- and lower-middle class socio-economically.

\subsection{Instruments and Materials}

\subsubsection{VIEW: An Assessment of Problem Solving Style}

VIEW (Selby, Treffinger, Isaksen, \& Lauer, 2004) is a 34-item self-report measure designed to assess six distinct problem solving styles across three broad dimensions of individuals' preferred approaches to dealing with problems, processing information, and making decisions. More than 20,000 individuals aged 12 through adulthood have taken VIEW, from a variety of countries and backgrounds. VIEW yields three scores: Orientation to Change (OC), Manner of Processing (MP), and Ways of Deciding (WD),

On OC, individuals can range from Explorer to Developer. An Explorer style prefers working without structure or authority, tends to look at the "big picture," and "welcomes the freedom to create and follow [his or her] own rules...." In contrast, a Developer is "enabled by structure and authority... [and] welcomes rules and guidelines." On MP, individuals can range between an External or Internal style. An External processor prefers social settings and interactions whereas an Internal processor “. $\ldots$ is engrossed in inner events and ideas, prefers working in quiet environments, and learns and works best when alone....” On WD, individuals can vary from a Person-oriented Style to Task-oriented Style. 
An individual with a People Style "sets priorities based on a more personal and caring kind of judgment [and] attends more to relationships and seeking harmony than to outcomes...." On the other hand, an individual with a Task Style "prefers well-reasoned conclusions and impersonal judgments [and] works persistently to achieve outcomes." Individuals can vary between extremes on each sub-scale and can, of course, display no preference or slight or moderate preferences as well as strong preferences (Selby et al., 2004).

Test-retest and Cronbach alpha reliabilities of VIEW are in the mid to high. 80 s and low 90s. Factor analyses support the three-factor structure and studies with other style and psychological variables demonstrate the construct validity of VIEW (Burger, Marino, Ponterotto, \& Houtz, 2008; Houtz, 2002; Houtz, Matos, Park, Scheinholtz, \& Selby, 2007; Houtz \& Selby, 2009; Houtz, Selby, Esquivel, Okoye, Peters, \& Treffinger, 2003a, 2003b; Shaw, Selby, \& Houtz, 2009).

\subsubsection{The COPE Inventory}

The COPE (Carver, Scheier, \& Weintrub, 1989) is a 60-item self-report measure designed to assess the dispositional tendencies of individuals to perform specific tasks when they are under stress. More than 15,000 individuals from college through adulthood have taken the COPE Inventory, also from a variety of countries and backgrounds.

The COPE yields three major scores and 15 subscores. The three major scores include Problem-focused Coping, Emotion-focused Coping, and Avoidance Coping. The Problem-focused Coping score consists of five (5) coping strategy subscores of Active Coping, Planning, Suppression of Competing Activities, Restraint Coping, and Seeking Instrumental Social Support. The Emotion-focused Coping score includes the coping strategy subscores of Seeking Emotional Social Support, Positive Reinterpretation and Growth, Acceptance, Denial, and Turning to Religion. The Avoidance Coping score includes the strategy subscores of Venting of Emotions, Mental Disengagement, and Behavioral Disengagement. There are two additional subscales of Use of Humor and Use of Illegal Substances.

Carvel et al. (1989) report a multifactor structure to COPE in accordance with the individual subscales, with two exceptions. Active Coping and Planning formed a single factor, as did Seeking Social Support for instrumental reasons and Seeking Social Support for emotional reasons. Reliabilities for the three major scales are reported in the .80 's. For the individual subscales, test-retest and alpha reliabilities range from .45 to .92 . Construct validity also is based on correlations with other personality measures (Carver et al., 1989).

\subsubsection{Problem Vignettes}

Case studies were selected from a variety of counseling training materials. The high stress case involved an individual of similar age to participants confronting a realistic, life-relevant problem with serious implications (a single mother entering the workforce after the death of her husband, and consequent changes in 
her children's school achievement). The low stress case involved an individual dealing with what may be considered a minor problem (selecting flowers for a date). The third group was given a short passage about geography.

\subsubsection{Stress Rating Scale}

A single-item 1- to 7-point scale was constructed to assess participants' perception of how stressful they perceived the situation to be in the vignette they were given. A higher rating indicated that participants perceived greater stress.

\subsubsection{Problem Solving Strategies Scale}

To assess participants' judgments of the usefulness of specific problem solving strategies, a 1- to 7-point rating scale for each of 12 strategies was constructed. Two strategies each were selected to represent the strategies most likely to be favored or rated highly by Explorers, Developers, External processors, Internal processors, Person-oriented Deciders, and Task-oriented Deciders, respectively. Strategy choices were made according to the theory behind the development of VIEW in regards the expectations of individuals with each of the six characteristic problem solving styles (Explorer, Developer, External, Internal, Person-oriented, Task-oriented). The senior author of VIEW was consulted in the selection process.

\subsubsection{Procedures}

Participants were contacted by the first author, their regular course instructor, and asked for their permission to participate in this research. Participation was not a course requirement. Those students who agreed to participate were then given a packet of materials to complete. The packet contained instructions, a demographic questionnaire and the VIEW and COPE instruments to complete first, then a problem vignette to read, and finally the stress and strategies rating scales.

In the packet, the order of VIEW and COPE was counterbalanced to control for ordering effects. The packets were randomly ordered so that the three experimental groups (that is, the three vignettes) would be approximately equally distributed in each classroom. High stress vignette participants were designated Group 1. Low stress participants were Group 2. Group 3 participants received the neutral passage, and since they were not given a problem situation, they were instructed to respond to the problem solving strategies scale as if they, themselves, faced a very important and difficult problem. Participants completed the packets after their class periods. Total time for completing the packet of materials was approximately 50 minutes.

\section{Results}

\subsection{Descriptive Statistics}

Table 1 presents the means, standard deviations, standard errors, minimum and maximum scores for VIEW and COPE scores. Tests of skewness and kurtosis 
Table 1. Means and standard deviations for COPE and VIEW Scales $(\mathrm{N}=107)$.

\begin{tabular}{|c|c|c|c|c|c|}
\hline & $M$ & $S D$ & SE & Min & Max \\
\hline \multicolumn{6}{|l|}{ VIEW } \\
\hline 1) Orientation to Change & 75.53 & 14.92 & 1.44 & 39 & 104 \\
\hline 2) Manner of Processing & 33.50 & 9.08 & .877 & 14 & 56 \\
\hline 3) Ways of Deciding & 32.31 & 7.83 & .757 & 9 & 52 \\
\hline \multicolumn{6}{|l|}{ COPE } \\
\hline 1) Positive Reinterpretation & 10.52 & 4.37 & .423 & 1 & 17 \\
\hline 2) Mental Disengage & 9.29 & 3.24 & .313 & 4 & 16 \\
\hline 3) Venting & 9.69 & 2.93 & .284 & 4 & 16 \\
\hline 4) Social Support & 9.84 & 2.72 & .263 & 4 & 15 \\
\hline 5) Active Coping & 11.90 & 3.28 & .317 & 4 & 17 \\
\hline 6, Denial & 8.54 & 3.25 & .314 & 4 & 15 \\
\hline 7) Religious & 9.76 & 3.78 & .365 & 2 & 17 \\
\hline 8) Humor & 8.93 & 3.19 & .308 & 4 & 16 \\
\hline 9) Behavior Disengage & 7.79 & 3.22 & .311 & 4 & 16 \\
\hline 10) Restraint & 9.64 & 3.84 & .371 & 4 & 17 \\
\hline 11) Emotional Support & 9.45 & 3.02 & .292 & 4 & 16 \\
\hline 12) Substance Use & 9.03 & 3.64 & .352 & 4 & 16 \\
\hline 13) Acceptance & 10.64 & 3.56 & .344 & 4 & 17 \\
\hline 14) Suppression & 10.09 & 3.58 & .346 & 4 & 17 \\
\hline 15) Planning & 10.25 & 3.52 & .341 & 4 & 16 \\
\hline 16) Problem-focused & 51.18 & 9.35 & .904 & 30 & 76 \\
\hline 17) Emotion-focused & 28.98 & 5.66 & .547 & 16 & 42 \\
\hline 18) Avoidance Coping & 44.94 & 7.73 & .747 & 30 & 73 \\
\hline
\end{tabular}

were computed via SPSS-17. None of the VIEW or COPE scores exceeded standard criteria for non-normality. There were gender differences on VIEW: males reported significantly lower grade point averages, and were significantly more Explorer and Task-oriented. There were no significant gender differences on age or Problem-focused, Emotion-focused, or Avoidance Coping.

\subsection{Reliability of VIEW and COPE}

Internal consistency estimates of VIEW and COPE Kuder-Richardson Formula 21 reliabilities were computed using participants' responses. For VIEW, reliability estimates were .91 (for Orientation to Change), .96 (for Manner of Processing), and .89 (for Ways of Deciding). For COPE, KR-21 reliability estimates for Problem-focused, Emotion-focused, and Avoidance Coping were .70, .34, and .57, respectively. KR21 reliability estimates for the 15 individual subscales ranged from -.21 to .51 , with an average of .20 .

\subsection{Intercorrelations among Study Variables}

Two-tailed Pearson correlations were computed among study variables. Signi- 
ficance was observed between age and Orientation to Change $(r=.243, p<.05)$ as well as grade point average and Orientation to Change $(r=.283, p<.01)$, suggesting that Developer problem-solving-styled students were older and reported higher grade-point-averages. The COPE subscale of Religion was significantly positively correlated with Ways of Deciding $(r=.296, p<.01)$, suggesting that Task-oriented deciders (as opposed to Person-oriented deciders) relied to a greater degree on faith or religion as a coping mechanism. The COPE Restraint subscale was negatively correlated with Orientation to Change $(r=-.200, p<.05)$ and Manner of Processing $(r=-.245, p<.05)$ but positively correlated with Ways of Deciding $(r=.279, p<.01)$. These correlations suggest that Explorers and External processors would hold back immediate actions during problem solving, and be open to input from others, but would still be Task-oriented; that is, they want to resolve their problem in the most reasonable and efficient way possible.

There were no significant intercorrelations among the three VIEW scores, but there were a number of significant intercorrelations among the COPE major and individual subscales. These are presented in Table 2 and may be of interest to users of the COPE instrument. Recall, however, that reported sub-scale reliabilities vary widely and are, in some cases, very low. In the present sample, the sub-scales do not appear to distinguish well between Problem-focused and Emotion-focused Coping.

Correlations between VIEW, Stress Level, and the dependent measures of problem solving strategy ratings were computed. Orientation to Change correlated positively with Stress Level $(r=.191, p<.05)$, suggesting that Developers perceived greater stress in the vignettes. In addition, a negative correlation with Explorer Strategy ratings $(r=-.365, p<.01)$ suggests that Explorer-styled students did, in fact, rate Explorer-type strategies more highly. Manner of Processing was positively correlated with Stress Level ratings $(r=.228, p<.05)$, suggesting that Internals perceived greater stress from the vignettes.

Next, correlations between COPE scores and the six problem solving strategy ratings were computed. Table 3 presents these results. Problem-focused Coping was significantly negatively related to Person-oriented and Task-oriented decision-making strategy ratings ( $r^{2} s=-.345$ and $-.347, p<.01$, respectively), suggesting that participants who relied on more problem-focused coping strategies were, simply, rating less desirable any of the decision-oriented strategies. Emotion-focused Coping was not correlated significantly with Stress ratings or any of

Table 2. Means and standard deviations of stress level ratings for the three experimental groups $(\mathrm{N}=107)$.

\begin{tabular}{ccccccc}
\hline & $\mathrm{N}$ & $\mathrm{M}$ & $\mathrm{SD}$ & $\mathrm{SE}$ & $\mathrm{Min}$ & Max \\
\hline High Stress Level & 41 & 5.768 & 2.037 & .318 & 2 & 13 \\
Low Stress Level & 32 & 3.562 & 2.699 & .477 & 1 & 15 \\
Neutral Stress Level & 34 & 1.765 & 1.075 & .184 & 0 & 5 \\
\hline
\end{tabular}


Table 3. Means and standard deviations of experimental groups on grade point average.

\begin{tabular}{ccccccc}
\hline & $\mathrm{N}$ & $\mathrm{M}$ & $\mathrm{SD}$ & $\mathrm{SE}$ & Min & Max \\
\hline High Stress Level & 37 & 3.31 & .457 & .075 & 2.40 & 4.00 \\
Low Stress Level & 29 & 3.11 & .608 & .113 & 1.35 & 4.00 \\
Neutral Stress Level & 30 & 2.52 & .907 & .166 & 0 & 3.60 \\
\hline
\end{tabular}

the six style strategy ratings. There was a positive correlation between Avoidance Coping and Explorer $(r=.255, p<.01)$ and Person-oriented $(r=.371, p<.01)$ strategy ratings, suggesting that participants who might be avoiding direct involvement in problem solving might also be choosing more divergent thinking strategies and/or avoiding decisions because of concerns about the impact of decisions on others.

There was a significant negative correlation between Stress Level and Positive Reinterpretation and Growth $(r=-.311, p<.05)$ and a negative correlation between Positive Reinterpretation and Growth and Explorer strategy ratings ( $r=$ $-.293, p<.01)$. Mental Disengagement and Explorer strategy ratings were positively correlated $(r=.245, p<.01)$. Religion was negatively correlated with Person-oriented strategy ratings $(r=.348, p<.01)$ and Task-oriented strategy ratings $(r=-.243, p<.05)$. Behavioral Disengagement was positively correlated with Explorer strategy ratings $(r=.313, p<.05)$, External strategy ratings $(r=.254$, $p<.05)$, and Person-oriented strategy ratings $(r=.251, p<.05)$.

Emotional Social Support and Developer strategy ratings were positively correlated $(r=.251, p<.05)$. Substance Use and Stress Level were negatively correlated $(r=-.234, p<.05)$. Substance Use and Person-oriented strategy ratings were positively correlated $(r=.265, p<.05)$. Acceptance and External strategy ratings were positively correlated $(r=.329, p<.01)$. Suppression of Competing Responses was negatively correlated with Internal strategy ratings $(r=-.340$, $p<.01)$ and Person-oriented strategy ratings $(r=-.371, p<.01)$. Additionally, Planning was negatively correlated with Explorer strategy ratings $(r=-.243$, $p<.05)$ and Person-oriented strategy ratings $(r=-.433, p<.01)$.

\subsection{Tests of Treatment Fidelity}

VIEW scores were transformed into dummy codes of " 1 " or " 2 " so that factorial analyses could be computed. For Orientation to Change, Manner of Processing, and Ways of Deciding, a dummy score of " 1 " was assigned if participants' VIEW scores were below the theoretical midpoint of the VIEW score ranges (below 72, 32 , and 32 on $\mathrm{OC}, \mathrm{MP}$, and WD, respectively). A dummy score of "2" was assigned if VIEW scores equaled or exceeded 72, 32, or 32, respectively. Table 4 presents the resulting descriptive statistics for the VIEW groups.

Then, three $2 \times 3$ factorial analyses of variance were computed with Stress Ratings as the dependent measure, and Group (High Stress Vignette, Low Stress Vignette, Neutral Condition)) and Orientation to Change code, Manner of Processing code, and Ways of Deciding code, respectively (two levels each), as 
Table 4. Descriptive statistics for VIEW groups created by dummy codes.

\begin{tabular}{ccccccc}
\hline & $\mathrm{N}$ & Mean & SD & SE & Min & Max \\
\hline Orientation to Change & & & & & & \\
Explorers & 37 & 58.892 & 9.530 & 1.567 & 39 & 72 \\
$\quad$ Developers & 70 & 84.329 & 8.233 & .984 & 73 & 104 \\
Manner of Processing & & & & & & \\
$\quad$ Externals & 48 & 25.271 & 5.115 & .738 & 14 & 32 \\
$\quad$ Internals & 59 & 40.186 & 5.28 & .687 & 33 & 56 \\
Ways of Deciding & & & & & & \\
Person-oriented & 55 & 26.673 & 5.299 & .714 & 9 & 32 \\
Task-oriented & 52 & 38.269 & 5.213 & .723 & 33 & 52 \\
\hline
\end{tabular}

the independent variables. In each analysis only the main effect of Group was significant $\left[F(\mathrm{OC})=25.18, F(\mathrm{MP})=32.43, F(\mathrm{WD})=35.62, d f^{\prime} \mathrm{s}=2,101, p\right.$ 's $<.01$ for each)]. Both Scheffe and Newman-Keuls post hoc tests revealed that in each analysis, the three experimental groups differed significantly from each other. Table 2 presents the means and standard deviations of the three experimental groups on Stress Level.

\subsection{Preliminary Tests for Potential Covariates}

A one-way ANOVA by Experimental Group (High Stress, Low Stress, Neutral Condition) was computed using Grade Point Average as the dependent measure. A significant $F=11.858(p<.01)$ was obtained. Post hoc comparisons using Scheffe and Newman-Keuls procedures revealed that the Neutral Group Grade Point Average was significantly lower than the other two groups (See Table 3). Therefore, in subsequent analyses Grade Point Average was used as a covariate.

\subsection{Tests of the Study Hypotheses}

Based on VIEW dummy coding described above, $t$-tests were computed between Explorers and Developers, between Externals and Internals, and between Person-oriented and Task-oriented Deciders on the actual VIEW scores (See Table 4). This was done to assure that the dummy coding process actually resulted in statistically significant differences between the respective means of the groups created. Developers did have higher scores on Orientation to Change $(t=$ $-14.385, d f=105, p<.00)$. Internals did have higher scores on Manner of Processing $(t=-14.166, d f=105, p<.00)$. Task-oriented Deciders did have higher scores on Ways of Deciding $(t=-11.404, d f=105, p<.00)$.

Results of the multivariate analyses of covariance. Three multivariate analyses of covariance were computed with Orientation to Change, Manner of Processing, and Ways of Deciding codes, respectively, used as one independent variable. Experimental group was the other independent variable and Grade Point Average was the covariate in each of the three analyses. The dependent variables were the Explorer, Developer, External, Internal, Person-oriented, and 
Task-oriented strategy ratings. The main effect of Experimental Group was significant in each analysis. The multivariate $F$-ratios were $3.077(p<.01), 2.268$ $(p<.05)$, and $2.407(p<.01)$, respectively, using the Wilks' Lambda statistic. The power statistics of these tests were $.988, .936$, and .951 , respectively. Eta-squares were $.278, .221$, and .231 , respectively.

There were no significant main effects due to the VIEW code variable. However, in the Group by Orientation to Change code MANCOVA, the interaction effect was significant at $p=.06$ when the criterion was Roy's Largest Root instead of Wilk's Lambda. The same interaction effect was significant at $p=.06$ for Roy's Largest Root when the MANCOVA involved Ways of Deciding and Group.

Results of the univariate analyses of covariance. Three $2 \times 3$ univariate factorial analyses of covariance were then computed using each of the six dependent measures, for a total of 18 analyses. Table 5 reports the $18 \mathrm{~F}$-ratios. As can be seen, the main effect of Experimental Group was significant in several cases. With Orientation to Change as one of the independent variables, Group showed differences on Explorer, Developer, Person-oriented, and Task-oriented strategy ratings. With Manner of Processing as one of the independent variables, Group

Table 5. Univariate factorial analyses of covariance for the six dependent measures using group and view codes as independent variables.

\begin{tabular}{|c|c|c|c|}
\hline & Effect & $F$ & $p$ \\
\hline With Orientation to Change Code & Group & & \\
\hline Explorer Ratings & & 3.527 & .05 \\
\hline Developer Ratings & & 5.683 & .01 \\
\hline External Ratings & & 2.165 & ns \\
\hline Internal Ratings & & 2.264 & $\mathrm{~ns}$ \\
\hline Person-oriented Ratings & & 11.308 & .01 \\
\hline Task-oriented Ratings & & 7.027 & .01 \\
\hline With Manner of Processing Code & Group & & \\
\hline Explorer Ratings & & 2.229 & $\mathrm{~ns}$ \\
\hline Developer Ratings & & 6.662 & .01 \\
\hline External Ratings & & 1.653 & ns \\
\hline Internal Ratings & & 2.081 & ns \\
\hline Person-oriented Ratings & & 7.299 & .01 \\
\hline Task-oriented Ratings & & 5.028 & .05 \\
\hline With Ways of Deciding Code & Group & & \\
\hline Explorer Ratings & & 1.631 & ns \\
\hline Developer Ratings & & 8.739 & .01 \\
\hline External Ratings & & 2.013 & ns \\
\hline Internal Ratings & & 1.548 & ns \\
\hline Person-oriented Ratings & & 6.723 & .01 \\
\hline Task-oriented Ratings & & 2.626 & .05 \\
\hline
\end{tabular}


was significant for Developer, Person-oriented, and Task-oriented strategy ratings. With Ways of Deciding as one independent variable, Group was significant for Developer and Person-oriented strategy ratings.

In no univariate analysis of covariance was the main effect of VIEW dimension statistically significant. However, the interaction effect of Orientation to Change and Group was statistically significant at $p<.05$ for Person-oriented and Task-oriented strategy ratings and significant at $p=.07$ for Explorer ratings. The interaction effect of Ways of Deciding and Group was significant at $p=.06$ on Developer strategy ratings.

Table 6 presents the means and standard deviations of the three experimental groups for the significant univariate effects. Regardless of which VIEW dimension is used as the second independent variable in the factorial analyses of covariance, the main effect means of the three experimental groups remain the same. Post hoc comparisons using the Scheffe and Newman-Keuls procedures revealed that for Developer strategy ratings, the Neutral group had significantly lower ratings that the High- or Low Stress groups. For Person-oriented strategy ratings, the Low Stress group had significantly higher ratings than the other two groups. Finally, for the Task-oriented strategy ratings, the Low Stress group had significantly higher ratings than the Neutral group.

\subsection{Additional Findings at the .10 Level of Statistical Significance}

As mentioned above, there were findings at the .06 and .07 levels of significance. Among the multivariate analyses, with Orientation to Change and with Ways of Deciding, the interaction effect of Group by VIEW code was significant at the .06 level. The power statistics of these two tests were .707 and .721 , respectively. Post hoc tests of the interaction effect revealed that the Low Stress Explorers rated the Explorer strategies more highly than did Low Stress Developers, High Stress Explorers and High Stress Developers. As for Developer strategy ratings, Low Stress, Task-oriented deciders gave higher ratings that did Neutral condition participants. Low Stress, Person-oriented deciders gave higher ratings than did Neutral condition, Task-oriented deciders. High Stress deciders (both Person- and Task-oriented) gave higher ratings than did Neutral condition, Task-oriented deciders.

Table 6. Means and standard deviations of the three experimental groups for the univariate tests (standard deviations in parentheses).

\begin{tabular}{cccc}
\hline & High Stress & Low Stress & Neutral \\
\hline Explorer Ratings & $3.362(1.051)$ & $4.022(1.118)$ & $4.000(.894)$ \\
Developer Ratings & $4.844(1.103)$ & $5.000(1.012)$ & $3.719(1.064)$ \\
External Ratings & $3.759(.979)$ & $4.286(.920)$ & $3.938(.998)$ \\
Internal Ratings & $3.586(1.196)$ & $4.167(.992)$ & $3.313(1.250)$ \\
Person-oriented Ratings & $3.845(1.095)$ & $4.801(.954)$ & $3.625(.885)$ \\
Task-oriented Ratings & $3.931(1.124)$ & $4.333(.730)$ & $3.250(1.197)$ \\
\hline
\end{tabular}




\subsection{A Note about the Above Analyses}

The reader is advised that the statistically significant results described above were neither eliminated nor added to when partial correlations or covariance analyses were computed using age and/or reported grade point average as control variables or covariates. Generally, changes in the actual magnitudes of various statistics amounted to a few decimal points.

\section{Discussion}

\subsection{Discussion of the Characteristics of Participants in Relation to VIEW and COPE}

Participants' scores on VIEW and COPE were distributed normally. Tests of skewness and kurtosis were not significant. However, participants' average Orientation to Change (75.53) was slightly above the VIEW hypothetical midpoint of 72. This suggests that participants in this study were slightly more Developer-like in their preferred style than Explorer. On Manner of Processing and Ways of Deciding, participants' means were much closer to the hypothetical midpoint score of 32. The slight Developer preference is well below the half standard deviation ( 9 points) described in the VIEW literature as indicating a marked preference in style (Selby et al., 2004).

As for the demographics of age and grade-point average, there were few individuals over 25, and few individuals reported low grade point averages. Presumably, individuals with very low averages would not be in school, or perhaps they would be reluctant to report a low GPA. Finally, there were more women than men (78 vs. 29) in the study, but this result is characteristic of the community college population and many higher education institutions today. The significant gender differences found in this study are not consistent with prior VIEW results (Selby et al., 2004) and suggest that more research is needed to understand these differences.

\subsection{Discussion of the Results Related to the Intercorrelations among VIEW Scores (Table 7)}

There were no findings of intercorrelation among the three VIEW scores. This outcome is supported by VIEW research which shows that among the more than 20,000 VIEW takers since its development, the scores of Orientation to Change, Manner of Processing, and Ways of Deciding are not significantly correlated (Selby et al., 2004). The internal consistency estimates for the three VIEW scores for this study also were similar to those reported in the VIEW literature.

\subsection{Discussion of Results Related to the Intercorrelations among COPE Scores (Table 8)}

The COPE scales did exhibit many significant intercorrelations. Carver, Scheier, and Weintrub (1989) expected and saw this in their own work. However, in the present study there was confusion across Problem-focused, Emotion-focused, 
Table 7. Intercorrelations among COPE major and individual sub-scales.

\begin{tabular}{|c|c|c|c|}
\hline Major COPE Scales: & Problem-focused & Emotion-focused & Avoidance Coping \\
\hline \multicolumn{4}{|l|}{ Sub-scales: } \\
\hline Positive Reinterpretation & $.225^{\star}$ & $.319^{*}$ & \\
\hline Mental Disengagement & $.507^{\star *}$ & $.258^{*}$ & $.214^{*}$ \\
\hline Instrumental Social Support & $.348^{\star *}$ & $.633^{\star *}$ & \\
\hline Emotional Social Support & $.199^{*}$ & $.665^{\star \star}$ & \\
\hline Active Coping & $.499^{* *}$ & $.326^{* *}$ & \\
\hline Acceptance & $.213^{*}$ & $.268^{*}$ & $.535^{\star *}$ \\
\hline $\begin{array}{l}\text { Suppression Competing } \\
\text { Responses }\end{array}$ & $503^{* *}$ & & \\
\hline Restraint & $.560^{\star \star}$ & & \\
\hline Planning & $.600^{* *}$ & $.216^{*}$ & \\
\hline Turning to Religion & $.352^{\star *}$ & & \\
\hline Denial & $.192^{*}$ & & $.289^{* *}$ \\
\hline Use of Illegal Substances & $-.196^{*}$ & & $.486^{* *}$ \\
\hline Venting & $.658^{\star *}$ & & \\
\hline Use of Humor & $.469^{* *}$ & & \\
\hline Behavioral Disengagement & $.502^{\star *}$ & & \\
\hline
\end{tabular}

${ }^{\star} p<.05,{ }^{* *} p<.01$.

Table 8. Correlations between COPE scores and strategy ratings.

\begin{tabular}{|c|c|c|c|c|c|c|}
\hline & Explorer & Developer & External & Internal & Person & Task \\
\hline Problem-focused Coping & & & & & $-.345^{\star *}$ & $-.347^{* *}$ \\
\hline Avoidance Coping & $.255^{\star *}$ & & & & $.371^{\star *}$ & \\
\hline Positive & & & & & & \\
\hline $\begin{array}{l}\text { Reinterpretation } \\
\text { and Growth }\end{array}$ & $-.293^{\star *}$ & & & & & \\
\hline Mental Disengagement & $.245^{\star *}$ & & & & & \\
\hline Religion & & & & & $-.348^{\star *}$ & $-.243^{*}$ \\
\hline $\begin{array}{c}\text { Behavioral } \\
\text { Disengagement }\end{array}$ & $.313^{* *}$ & & $.254^{\star}$ & & $.251^{*}$ & \\
\hline $\begin{array}{c}\text { Emotional } \\
\text { Social Support }\end{array}$ & & $.251^{*}$ & & & & \\
\hline Substance Use & & & & & $.265^{*}$ & \\
\hline Acceptance & & & $.329^{* *}$ & & & \\
\hline $\begin{array}{c}\text { Suppression } \\
\text { Competing Responses }\end{array}$ & & & & $-.340^{* *}$ & $-.371^{* *}$ & \\
\hline Planning & $-.243^{*}$ & & & & $-.433^{\star *}$ & \\
\hline
\end{tabular}


and Avoidance Coping. Several individual scales correlated significantly with more than one of the three major subscales, and some did not correlate with their expected major subscale at all. While the participants in this study were younger than those reported in the original COPE literature, their overall mean scores and standard deviations on the individual subscales were similar in most cases to those reported by Carver et al. (1989). However, the subscore reliability estimates for these participants were very low, and such may be the best reason for the confusion between the three major scales.

It was not the main purpose of this study to examine the COPE instrument in detail, but it is worth noting that the average Problem-focused score for these participants was almost twice that of their Emotion-focused average. Recall that the COPE measure was administered before anyone read a vignette, so one may assume that participants were not experiencing any problem or stress beyond what they may be bringing with them from their own lives or as students in an academic class. One might surmise that this difference might best be explained by the fact that participants were, in general, disposed to think dispassionately precisely because of the task at hand-that is, participating in a research study on a volunteer basis, a task that appeared to involve "academic" behavior (reading and answering questions), and was not affecting their grades or their personal lives.

\subsection{Discussion of Results Related to Correlations between VIEW and COPE Scores}

The greatest disappointment in this study was the lack of significant correlation between VIEW and the main COPE scales of Problem-focused, Emotion-focused, and Avoidance Coping styles. However, there were a few correlations with the individual subscales that are consistent with VIEW theory. The COPE subscale of Restraint, implying less immediate, more considered action, was correlated negatively with each of the VIEW scales. In other words, individuals with a more Explorer, External, and Person-oriented problem solving style were rating themselves more highly on this scale. Restraint is considered by Lazarus and Folkman (1984) to be a Problem-focused coping strategy. Individuals who make use of problem-focused mechanisms perceive problems as "opportunities for benefit or gain... believe that problems are solvable... and believe [in their] personal ability to solve problems successfully" (p. 101). Thus, such individuals are motivated and involved, and consequently invest more time and effort.

In VIEW theory, Explorer strategies, External processing, and Person-oriented deciding necessarily take more time. So-called "outside-the-box" thinking requires more time because many new and different ideas are suggested beyond the "tried-and-true" routines. External processing requires more time because Externals typically are motivated and energized by interactions with others, and seek such interactions and additional information and ideas, thus taking more time. Finally, when making decisions, taking into consideration the impact of 
solution choices on other people, as Person-oriented Deciders are wont to do, adds another criterion to the process. This, too, takes time.

An additional correlation between Orientation to Change and participants' ratings of problem solving strategies also is significant. Orientation to Change and ratings of Explorer-type strategies were correlated negatively, implying that Explorers overall were rating Explorer-type strategies as more likely to be successful. Only one other VIEW-COPE correlation was significant, that between Ways of Deciding and the COPE scale of Religion. This correlation was positive, suggesting that Task-oriented individuals rated more highly turning to religion to respond to a stressful problem situation. A plausible explanation for this correlation is that religious faith typically provides "answers of certainty," of what is right and true and, consequently, offering guidance as well as comfort. Those qualities of clarity and rightness are thought in VIEW theory to appeal to individuals who prefer to make decisions based on greater efficiency and certitude as to what works. Also, for Person-oriented deciders, worry about the effects of different solution choices on people may be minimized, because faith in a higher power, for example, includes the belief that the person's needs will be provided by that power.

\subsection{Discussion of Intercorrelations among Participants' Ratings of Problem Solving Strategies}

Among the 15 possible correlations among the six ratings of problem solving strategies (Explorer, Developer, External, Internal, Person-oriented, and Task-oriented strategies), nine were statistically significant and positive. Overall, the median correlation among the six ratings was .282 $(p<.05)$. For this reason, multivariate analyses were computed. Of interest, however, was the lack of significant correlation between participants' ratings of Explorer and Developer strategies. But, External and Internal and Person-oriented and Task-oriented ratings were significantly positively correlated. A possible explanation for this based on VIEW theory rather than chance is that participants perceived the greatest "difference" between Explorer and Developer strategies, such that if one were to choose an Explorer strategy, for example, one would not see a corresponding Developer strategy as appropriate.

The VIEW instrument contains more than twice as many items keyed to Orientation to Change as do the Manner of Processing and Ways of Deciding scales. Thus, Explorers and Developers have a greater chance of distinguishing themselves on VIEW. In turn, Explorers and Developers have a better chance of perceiving more positively those strategies that better "match" their respective styles. Thus, they are less likely to rate different strategies in a similar way.

\subsection{Discussion of Results Related to the Multivariate Analyses}

There were no main effects of problem solving style on any of the six problem solving strategy ratings for each of the three analyses computed using VIEW 
dummy codes an independent variable. Considering that the overall MANCOVA power levels exceeded .90 , it is a safe assumption that the overall effect of style was not strong enough, if it existed at all in this study, to affect participants' ratings. Effect sizes for the dichotomous breakdowns of OC, MP, and WD were, respectively, .049, .141, and .157, with power levels of .155, .464, and .524 .

There were limitations to this study, discussed below, that might have contributed to a lack of main effects. However, there was an interaction effect at the .10 level, with power of .70. Admittedly, this level of significance does not meet the generally accepted standard alpha of .05 . However, the result that stands out is that participants in the less stressful condition did give higher ratings to Explorer-type strategies on the questionnaire after reading the problem vignette. On its face, this result makes sense. Individuals who perceive that a problem is of lesser seriousness, perhaps posing less of a threat of dire consequences, may be more willing to try newer strategies, break a few rules, go in "different" directions from what they are used to. The converse also may be true. Individuals experiencing greater stress may be less willing or able to think and act "divergently." The overall literature on creative problem solving and idea generation supports this explanation (Feldhusen \& Goh, 1995; Houtz, 1990; Osborn, 1963; Sternberg \& Lubart, 1995; Torrance, 1986; Treffinger, 1997). In this regard, the work of Hennessey (Hennessey, 1989; Hennessey \& Amabile, 1998; Hennessey \& Zbikowski, 1993) with individual problem solvers working under conditions of "surveillance" and evaluation strongly suggests that such negative environmental factors can inhibit idea generation substantially.

\subsection{Discussion of Results Related to the Main Effect of Vignette}

In this study there was a main effect in each analysis due to the effect of the vignettes. In each of the three factorial analyses using one of the VIEW factors and stress condition as independent variables, participants rated the high stress vignette as significantly more stressful than the low stress vignette. In addition, the neutral condition was rated lowest in perceived stress.

In terms of treatment fidelity, this finding was not surprising. As mentioned previously, case vignettes have successfully been used to change mood perception in a variety of research studies (Hjortso et al., 1989). The importance of this result in the present study is that it supports the view that participants were attending to the directions given by this researcher, and that, by inference, were providing responses in a serious and truthful manner. Of those individuals who participated in the study, there were no papers that had to be discarded because of obviously irrelevant responses.

With regard to overall stress ratings, however, there were two interesting correlations. VIEW scores of Orientation to Change $(r=.191, p<.05)$ and Manner of Processing $(r=.228, p<.05)$ were significantly correlated with Stress Level Ratings. In other words, both Developers and Internals perceived higher stress levels than Explorers and Externals. 
These findings also are not surprising. Developers are not rule-breakers; they prefer structure, clarity. The vignette problems are "divergent" in nature. They are a "fuzzy," ill-defined type of problem that has no obvious solution, offers limited background information, no clear pathway to a suitable answer, and no criteria for what may constitute a "best" solution. To this type of problem, Developers are more likely to respond with a sense of unease or discomfort, and stressful feelings. Similarly, by nature internal processors mull over thoughts to themselves for a time. They think through and "test" out their own ideas first. They look "inward" for inspiration in their own private "space." But, that private time contains the burden of holding inward any stressful feelings before being able to allow others to share the burden.

These explanations suggest simply that Developers and Internals are more sensitive to conditions that present with more ambiguity and uncertainty. By extension, Explorers and Externals may actually react well to "fuzzy" ambiguity. They may see such a condition as "freeing," as an opportunity to create their own rules (Explorers) and/or engage socially with others (Externals) in a problem solving enterprise.

\section{Conclusion}

Problem solving style, as measured by VIEW, and the major constructs measured by COPE (that is, Orientation to Change, Manner of Processing, Ways of Deciding, Problem-focused Coping, Emotion-focused Coping, and Avoidance Coping) do not appear to be related. A few COPE subscales and VIEW correlations do offer some evidence for theoretical links.

In contrast, the results for strategy ratings after reading a vignette were clearer. For example, Explorers rated Explorer-type strategies more highly; Developers and Internal processors perceived greater stress in the vignettes; and individuals in the less stressful condition rated the strategies higher in general.

There is no doubt by now that there exist different styles and strategies for dealing with problems. More research is needed to uncover and understand when, how, and why styles and strategies may complement or inhibit one another. Almost daily, we hear the call from leaders in government and industry, from all segments and levels of our society, for more creative problem solvers in our ever more complex and uncertain, competitive and fast-paced world. Better answers will come, almost certainly, by continued study of how problem solving style affects people's perception of problems, their ways of seeking and processing information, and the choices they make and the strategies they use to act on those choices.

\section{References}

Anderson, J. R. (1982). Acquisition of Cognitive Skills. Psychological Review, 89, 369-406. https://doi.org/10.1037/0033-295X.89.4.369

Basadur, M., Graen, G., \& Wakabayashi, M. (1990). Identifying Individual Differences in Creative Problem Solving Style. Journal of Creative Behavior, 24, 111-131. 
https://doi.org/10.1002/j.2162-6057.1990.tb00533.x

Borko, H., \& Livingston, C. (1989). Cognition and Improvisation: Differences in Mathematics Instruction by Expert and Novice Teachers. American Education Research Journal, 26, 473-498. https://doi.org/10.3102/00028312026004473

Bransford, J. D., \& Stein, B. S. (1984). The IDEAL Problem Solver: A Guide for Improving Thinking, Learning, and Creativity. New York, NY: W. H. Freeman.

Burger, C., Marino, C., Ponterotto, J., \& Houtz, J. (2008). Problem Solving Style and Multicultural Personality Dispositions. Creative Learning Today, 16, 2-3.

Carver, C. S., Scheier, M. F., \& Weintraub, J. D. (1989). Assessing Coping Strategies: A Theoretically Based Approach. Journal of Personality and Social Psychology, 56, 283. https://doi.org/10.1037/0022-3514.56.2.267

Dewey, J. (1910). How We Think. Boston, MA: Heath. https://doi.org/10.1037/10903-000

Feldhusen, J. F., \& Goh, B. E. (1995). Assessing and Accessing Creativity: An Integrative Review of Theory, Research, and Development. Creativity Research Journal, 8, 231-247. https://doi.org/10.1207/s15326934crj0803_3

Folkman, S., \& Lazarus, R. S. (1988). Ways of Coping Questionnaire: Research Edition. Palo Alto, CA: Consulting Psychologists Press.

Guilford, J. P. (1967). The Nature of Human Intelligence. New York, NY: McGraw-Hill.

Hayes, J. R. (1981). The Complete Problem Solver. Philadelphia, PA: The Franklin Institute Press.

Hennessey, B. A. (1989). The Effects of Extrinsic Constraints on Children's Creativity while Using a Computer. Creativity Research Journal, 2, 151-168.

https://doi.org/10.1080/10400418909534312

Hennessey, B. A., \& Amabile, T. M. (1998). Reward, Intrinsic Motivation, and Creativity. American Psychologist, 53, 674-675. https://doi.org/10.1037/0003-066X.53.6.674

Hennessey, B. A., \& Zbikowski, S. M. (1993). Immunizing Children against the Negative Effects of Reward: A Further Examination of Intrinsic Motivation Training Techniques. Creativity Research Journal, 6, 297-307.

https://doi.org/10.1080/10400419309534485

Hjortso, S., Butler, B., Clemmesen, L., Jepsen, P. W., Kastrup, M., Vilmar, T., \& Bech, P. (1989). The Use of Case Vignettes in Studies of Interrelated Reliability of Psychiatric Target Syndromes and Diagnoses: A Comparison of ICD-8, ICD-10, and DSM-III. Acta Psychiatrica Scandinavica, 80, 632-638. https://doi.org/10.1111/j.1600-0447.1989.tb03036.x

Houtz, J. C. (1990). Environments That Support Creative Thinking. In C. Hedley, J. Houtz, \& A. Baratta (Eds.), Cognition, Curriculum, and Literacy (pp. 61-76). Norwood, NJ: Ablex.

Houtz, J. C. (2002). Creativity Style Makes a Difference in Problem Solving. Creative Learning Today, 11, 7-9.

Houtz, J. C., \& Selby, E. C. (2009). Problem Solving Style, Creativity, and Problem Solving Confidence. Educational Research Quarterly, 33, 18-30.

Houtz, J. C., Matos, H., Park, M. K., Scheinholtz, J., \& Selby, E. (2007). Problem Solving Style and Motivational Attributions. Psychological Reports, 101, 823-830. https://doi.org/10.2466/pr0.101.3.823-830

Houtz, J. C., Selby, E., Esquivel, G. E., Okoye, R. A., Peters, K., \& Treffinger, D. J. (2003a). A Comparison of Two Creativity Style Measures. Perceptual and Motor Skills, 96, 288-296. https://doi.org/10.2466/pms.2003.96.1.288 
Houtz, J. C., Selby, E., Esquivel, G. E., Okoye, R. A., Peters, K., \& Treffinger, D. J. (2003b). Creativity Style and Personality Type. Creativity Research Journal, 15, 321-330. https://doi.org/10.1207/S15326934CRJ1504_2

Isaksen, S. G., \& Dorval, K. B. (1993). Toward an Improved Understanding of Creativity within People: The Level-Style Distinction. In S. G. Isaksen, M. C. Murdock, R. L. Firestein, \& D. J. Treffinger (Eds.), Understanding and Recognizing Creativity: The Emergence of a Discipline (pp. 299-330). Norwood, NJ: Ablex.

Isaksen, S. G., \& Treffinger, D. J. (2004). Celebrating 50 Years of Reflective Practice: Versions of Creative Problem Solving. Journal of Creative Behavior, 38, 75-101. https://doi.org/10.1002/j.2162-6057.2004.tb01234.x

Johnson, D. M. (1955). The Psychology of Thought and Judgment. New York, NY: Harper \& Row.

Johnson, D. M. (1972). The Psychology of Thought and Judgment (3rd ed.). New York, NY: Harper \& Row.

Kirton, M. (1994). Adaptors and Innovators: Styles of Creativity and Problem Solving (Revised Edition). London: Routledge.

Lazarus, R. S., \& Folkman, S. (1984). Stress, Appraisal, and Coping. New York, NY: Springer.

Neisser, U. (1966). Cognitive Psychology. New York, NY: Appleton-Century-Crofts.

Newell, A., \& Simon, H. A. (1972). Human Problem Solving. Englewood Cliffs, NJ: Prentice-Hall.

Osborn, A. F. (1963). Applied Imagination: Principles and Procedures of Creative Problem Solving (3rd rev. ed.). New York, NY: Charles Scribner's Sons.

Polya, G. (1945/1957). How to Solve It: A New Aspect of Mathematical Method. Princeton, NJ: Princeton University Press.

Rossman, J. (1931). The Psychology of the Inventor. Washington DC: Inventors Publishing Co.

Selby, E. C., Treffinger, D. J., Isaksen, S. G., \& Crumel, J. H. (2007). An Introduction to Problem-Solving Style. Sarasota, FL: Center for Creative Learning, Inc.

Selby, E. C., Treffinger, D. J., Isaksen, S. G., \& Lauer, K. J. (2004). Defining and Assessing Problem-Solving Style: Design and Development of a New Tool. Journal of Creative Behavior, 38, 221-243. https://doi.org/10.1002/j.2162-6057.2004.tb01242.x

Shaw, E. J., Selby, E. C., \& Houtz, J. C. (2009). Problem Solving Style and Beliefs about Teaching, Learning, and Problem Solving. Creativity Research Journal, 21, 394-399. https://doi.org/10.1080/10400410903359798

Sternberg, R. J. (2000). Thinking Styles. New York, NY: Cambridge University Press.

Sternberg, R. J., \& Horvath, J. A. (1995). A prototype of Expert Teaching. Educational Researcher, 24, 9-17. https://doi.org/10.3102/0013189X024006009

Torrance, E. P. (1986) Teaching Gifted and Creative Learners. In M. C. Wittrock (Ed.), Handbook of Research on Teaching (3rd ed., pp. 630-647). New York, NY: Macmillan.

Treffinger, D. J. (1988). A Model for Creative Learning: 1988 Update. Creative Learning Today, 2, 4-6.

Treffinger, D. J. (1997). Productive Thinking, Curriculum, and Instruction. Creative Learning Today, 7, 1-2.

Treffinger, D. J., Isaksen, S. G., \& Dorval, K. B. (2006). Creative Problem Solving: An Introduction (3rd ed.). Sarasota, FL: Center for Creative Learning, Inc.

Wallas, G. (1926). The Art of Thought. London: Watts. 